\title{
A Multiplicidade de Papéis da Mulher Contemporânea e a Maternidade Tardia
}

\author{
Manuela Nunes Lopes \\ Faculdades Integradas de Taquara, Taquara, Rio Grande do Sul, Brasil \\ Letícia Lovato Dellazzana-Zanon \\ Universidade Federal do Rio Grande do Sul, Porto Alegre, Rio Grande do Sul, Brasil \\ Mariana Gonçalves Boeckel ${ }^{1}$ \\ Universidade Federal de Ciências da Saúde de Porto Alegre, Porto Alegre, Rio Grande do Sul, Brasil
}

\begin{abstract}
Resumo
A mulher atual assumiu muitos papéis antes desempenhados pelos homens, o que trouxe mudanças não apenas para sua rotina, mas também para seus projetos de vida. A maternidade tem sofrido o impacto dessas mudanças. Investigaram-se os múltiplos papéis exercidos pela mulher contemporânea e a relação dessa multiplicidade de papéis com a maternidade tardia. Utilizaram-se dois instrumentos: ficha de dados sociodemográficos e entrevista semiestruturada sobre a multiplicidade de papéis da mulher e sobre maternidade. Construíram-se três categorias a partir da análise de conteúdo: multiplicidade de papéis da mulher contemporânea, reflexões sobre maternidade e maternidade tardia versus rotina atual. Se por um lado, as mulheres sofrem prejuízos em função do excesso de tarefas, por outro, elas se sentem felizes por ocuparem seus postos de trabalho. A maternidade tardia é uma opção para mulheres que trabalham e que mantém relações estáveis com seus companheiros. Entretanto, observaram-se sentimentos como medo, insegurança e ambivalência em relação à maternidade tardia.
\end{abstract}

Palavras-chave: Mulher, maternidade tardia, família.

\section{The Multiple Roles of Contemporary Women and Late Motherhood}

\begin{abstract}
Women currently have taken on many roles, previously filled by men, which not only changed their everyday lives but also impacted their life projects. Motherhood has been impacted in important ways by this change. We investigated the multiple roles played by contemporary woman and the relation between this multiplicity of roles and late motherhood. Two instruments were used: a socio-demographic profile and a semi-structured interview about the multiple roles of women and motherhood. We constructed three categories based on content analysis of the interviews: the multiple roles of contemporary women; reflections on motherhood; and late motherhood's impact on current routine. If, on one hand, women are negatively affected due to the additional workload, on the other they feel happy to have developed a career. Late motherhood is an option for women who intend to develop their careers and maintain stable relationships with their partners. However, the women also reported feelings such as fear, insecurity and ambivalence related to late motherhood.
\end{abstract}

Keywords: Woman, late motherhood, family.

Endereço para correspondência: Rua Sarmento Leite, 245/sala 207, prédio Central - Porto Alegre, Rio Grande do Sul, Brasil - CEP 90050-170. E-mail: manuelanuneslopes@gmail.com, leticiadellazzana@gmail.com e marianagb@ufcspa.edu.br 


\section{Las Múltiples Funciones de la Mujer Contemporánea y la Maternidad Tardía}

\section{Resumen}

La mujer actual adoptó muchos papeles que antes eran realizados por los hombres; esto produjo cambios no solamente en su rutina, sino proporcionó cambios en sus proyectos de vida. La maternidad ha sufrido el impacto de esos cambios. Fueron investigados los múltiples papeles que ejercen la mujer contemporánea y la relación de esa multiplicidad de papeles con la maternidad tardía. Se utilizaron dos instrumentos: una ficha de datos sociodemográficos y una entrevista semiestructurada sobre la multiplicidad de los papeles de la mujer y sobre la maternidad. Fueron construidas tres categorías a partir del análisis de contenido: multiplicidad de papeles de la mujer contemporánea, reflexiones sobre la maternidad y maternidad tardía versus rutina actual. Si, de un lado, las mujeres sufren pérdidas en función del exceso de tareas, de otro, ellas se sienten felices por ocupar sus puestos de trabajo. La maternidad tardía es una opción para mujeres que trabajan y que mantienen relaciones estables con sus compañeros. Sin embargo, se observaron sentimientos como miedo, inseguridad y ambivalencia en relación a la maternidad tardía.

Palabras clave: Mujeres, maternidad tardía, familia.

A mulher atual tem assumido uma serie de papéis que antes se referiam prioritariamente aos homens. Tal fato trouxe mudanças não apenas para a rotina da mulher contemporânea, mas também para seus projetos de vida e suas consequentes escolhas. Uma das áreas que sofreu um impacto importante em função da multiplicidade de papéis assumidos pela mulher da atualidade é a maternidade. Em função de todas as demandas relacionadas à carreira e ao estudo, o projeto de ter filhos tem sido sistematicamente adiado. Conhecer o que as mulheres que desempenham múltiplos papéis pensam sobre esta questão e sobre a maternidade tardia pode contribuir para o entendimento deste fenômeno tão presente em nossa sociedade, bem como servir de base para o atendimento clínico de mulheres que sofrem em decorrência destas questões.

Os papéis parecem designar quem o ser humano será ao longo de sua trajetória de vida. Desde crianças, meninos e meninas ouvem o que devem ou não fazer. Desde a mais tenra idade, recebe-se da família um conjunto de regras e normas que comportam papéis pré-estabelecidos e que narram uma história já construída para mulheres e homens por grupos sociais de épocas anteriores (Fleck, Falcke, \& Hackner, 2005). Quanto às mulheres, pode-se dizer que sempre foram consideradas o centro da família como consequência dos papéis exercidos como mãe e esposa. Vistas como cuidadoras, primeiro dos homens, depois das crianças e, por fim, dos idosos, exerciam papéis de esposa, filha e mãe. Dependendo do status social do grupo, bem como do provento do homem, ocupavam mais ou menos espaços como servidoras dele (Carter \& McGoldrick, 2008).

Havia uma divisão clara de papéis: o homem era o provedor do lar, com autonomia para estabelecer regras e delegar funções e a mulher era a cuidadora doméstica, reclusa às atividades desenvolvidas unicamente dentro de casa (Fleck \& Wagner, 2003). Atualmente, não se observa mais esta divisão, uma vez que a realidade da família de classe média dos séculos XIX e XX sofreu mudanças em relação aos papéis desempenhados por cada um de seus membros. Ao longo das últimas décadas, a mulher contemporânea vem acrescentando novas funções ao seu estilo de vida, assumindo, por exemplo, posições no mercado de trabalho, antes só ocupadas por homens. Supõe-se que essas transformações na dinâmica familiar possam ter sido influenciadas por fatores como economia e tecnologia, as quais se movimentam continuamente ao longo do tempo (Fleck \& Wagner, 2003).

No que se refere à dinâmica familiar, podem ser observados dois momentos distintos: 
o modelo antigo e o atual (Negreiros \& Féres-Carneiro, 2004). No primeiro, o sexo feminino e o masculino eram distintamente separados pelas atribuições diferenciadas dos papéis. Cabia ao homem o trabalho e a virilidade como formas de sustentar e manter a família. À mulher, era atribuído o papel de esposa cuidadora e fiel, a qual se preocupava em preservar sua sexualidade, mantendo-se virgem antes do casamento e dedicando-se à maternidade e ao lar. No modelo atual de família, as fronteiras parecem ser mais flexíveis entre ambos os sexos, havendo outras possibilidades de papéis tanto para os homens como para as mulheres. Sabe-se, inclusive, que tem ocorrido troca nesses papéis: em alguns lares a mulher é o chefe da família, enquanto o homem fica em casa para cuidar dos filhos (Negreiros \& Féres-Carneiro, 2004).

Assim, a mulher contemporânea saiu da segurança do lar e tem enfrentado o mercado de trabalho em busca de novas possibilidades, novas conquistas e novos modelos de vida. Esta mudança do status da mulher pode ser resultante da autonomia conquistada através de sua atuação fora do lar. A mulher passou a se estruturar como um indivíduo mais valorado, criando um novo olhar para si, diferente daquele concebido até metade do século XX (Maux \& Dutra, 2009). Esta mudança quanto aos papéis demonstra que houve uma quebra de velhos paradigmas impostos pela sociedade, bem como um distanciamento significativo daqueles de tempos passados (Badalotti \& Petracco, 1997). Consequentemente, a família também mudou sua configuração, uma vez que os valores familiares deixaram de se fundamentar apenas no homem, passando, então, a serem divididos com a mulher (Hintz, 2001). Portanto, pode-se pensar que a postura adotada pela mulher contemporânea - de sair do lar para provê-lo - acarretou mudanças significativas na estrutura familiar e no modo como seus integrantes lidam com esta situação (Grzybowski, 2002).

Um dos âmbitos no qual é possível observar mudanças em função da multiplicidade de papéis da mulher na atualidade é a maternidade. Nesse sentido, projetos de vida em relação à maternidade têm sido preteridos e postergados em função de atividades de ordem profissional (Souza, Teixeira, Loreto, \& Bartolomeu, 2011). Este é o contexto da maternidade tardia.

Considera-se maternidade tardia quando a concepção ocorre após os 35 anos de idade. De acordo com a literatura médica, a mulher que decide engravidar na fase final da terceira década de vida é considerada uma mãe idosa, uma vez que, a partir dos vinte e sete anos, há uma baixa hormonal significativa (Barbosa \& Rocha-Coutinho, 2007; Gomes, Donelli, Piccinini, \& Lopes, 2008). Existe, portanto, uma preocupação de alguns profissionais da saúde sobre essa questão devido aos riscos de má formação fetal e possíveis prejuízos para a gestante (Barbosa \& Rocha-Coutinho, 2007; Gomes et al., 2008).

De fato, a partir dos 35 anos há um maior risco de adversidades para a gestação, o qual aumenta consideravelmente após os 40 anos de idade e assim sucessivamente (Zavaschi, Costa, Brunstein, Kruter, \& Estrella, 1999). A idade ideal para a gestação se compara com a idade atlética, pois o corpo envelhece e perde capacidades essenciais para um adequado desenvolvimento gestacional. Estende-se a esse pressuposto a realidade de que uma mulher com idade superior a 35 anos, possivelmente não apresente mais a mesma disposição física e o vigor exigidos pela maternagem (Moreira \& Rasera, 2010). Há uma probabilidade, nesse sentido, de que uma mulher mais velha tenha maiores dificuldades para lidar com crianças na primeira infância, uma vez que isto demanda prontidão, energia, cuidados incessantes e agilidade para o exercício da maioria das atividades (Cecatti, Aquino, \& Faúndes, 2000). Em função da associação entre maternidade tardia e possíveis riscos inerentes à idade da mãe, observa-se que a gestação, neste contexto, está mais vinculada ao serviço especializado de médicos, psicólogos e outros profissionais da saúde (Moreira \& Rasera, 2010; Schupp, 2006).

Em contrapartida, estudos indicam que há benefícios na maternidade em idade avançada (Lima, 2010; Souza et al., 2011; Zavaschi et al., 1999). Apesar dos riscos explicitados pela medicina e da multiplicidade de tarefas da mulher, observa-se que as gestantes tardias têm maiores 
condições econômicas, sociais e emocionais para se tornarem mães. Elas usufruem de uma rede de apoio importante, conquistada por meio do exercício de diversas atividades desempenhadas anteriormente e parecem conciliar com maior equilíbrio suas tarefas domésticas e laborais (Souza et al., 2011). Mulheres com mais de 35 anos podem usufruir de um nível socioeconômico mais elevado, bem como dispor de condições comportamentais e emocionais mais estáveis, características essenciais para uma boa gestação (Lima, 2010). Desta forma, faz-se necessário entender o cotidiano da mulher que exerce múltiplos papéis e que opta pela maternidade tardia, uma vez que esta é uma situação recorrente vivenciada por muitas mulheres na contemporaneidade. Partindo disso, este artigo teve como objetivos investigar qualitativamente: (a) os múltiplos papéis exercidos pela mulher contemporânea e (b) qual a relação da multiplicidade de papéis exercidos pela mulher com a maternidade tardia.

\section{Método}

\section{Participantes}

Participaram deste estudo quatro mulheres de nível socioeconômico médio, residentes na cidade de Porto Alegre/RS. Utilizou-se o critério de saturação (Bauer \& Gaskell, 2002) para definir o número de participantes. Quando a quarta entrevista foi realizada, observou-se que as informações estavam se repetindo e que não surgiam conteúdos novos, razão pela qual o processo de seleção de novas participantes foi interrompido. Utilizaram-se os seguintes critérios de inclusão: (a) idade entre 35 e 40 anos, (b) escolaridade mínima ser nível superior em andamento, (c) exercício laboral remunerado (c) vida marital compartilhada há pelo menos dois anos e (d) ausência de filhos. A caracterização das participantes pode ser vista na Tabela 1. Considerando-se os cuidados éticos, o nome e todas as informações que pudessem caracterizar as participantes foram trocados.

Tabela 1

Caracterização das Participantes

\begin{tabular}{|c|c|c|c|c|c|c|}
\hline Nome & $\begin{array}{l}\text { Idade } \\
\text { (anos) }\end{array}$ & Escolaridade & Curso & $\begin{array}{l}\text { Tempo } \\
\text { estudo } \\
\text { semanal }\end{array}$ & $\begin{array}{l}\text { Tempo } \\
\text { trabalho } \\
\text { semanal }\end{array}$ & $\begin{array}{c}\text { Tempo } \\
\text { de relação }\end{array}$ \\
\hline Ana & 38 & Superior incompleto & Gestão de RH & $8 \mathrm{hs}$ & $44 \mathrm{hs}$ & 8 anos \\
\hline Diana & 35 & Superior incompleto & Relações públicas & $12 \mathrm{hs}$ & $70 \mathrm{hs}$ & 8 anos \\
\hline Laura & 35 & Pós-doutorado incompleto & Pós-doutorado & $56 \mathrm{hs}$ & $84 \mathrm{hs}$ & 5 anos \\
\hline Paula & 35 & $\begin{array}{l}\text { Superior completo/pós- } \\
\text { graduação completo/curso } \\
\text { de pilotagem incompleto }\end{array}$ & $\begin{array}{c}\text { Psicologia e curso } \\
\text { de pilotagem }\end{array}$ & $10 \mathrm{hs}$ & 44hs & $\begin{array}{l}2 \text { anos } \\
\text { e } 2 \text { meses }\end{array}$ \\
\hline
\end{tabular}

\section{Instrumentos}

Utilizaram-se os seguintes instrumentos: (a) ficha de dados sociodemográficos e (b) entrevista semiestruturada sobre a multiplicidade de papéis da mulher e sobre maternidade. Inicialmente, leu-se o seguinte rapport: "A mulher do século XXI é um indivíduo diferenciado dentre as gerações que a antecederam. Exerce atividade laboral fora do lar, tem compromisso marital e continua atuando nos afazeres domésticos". Então, iniciou-se a entrevista com as seguintes perguntas: (a) Como você percebe essas mudan- ças? (b) Discorra sobre sua rotina semanal (c) Quais as atividades mais desempenhadas, por você, nos últimos dois anos? (d) Você percebe alguma delas como mais importante? (e) Qual o impacto dessa atividade em outras áreas de sua vida - conjugal, familiar, com o grupo de amigos/colegas e nas horas de lazer? (f) Alguma delas já acarretou algum prejuízo pra você? Em caso afirmativo, quais? (g) Você pensa em ser mãe? Em caso negativo, por quê? Em caso afirmativo, em que momento de sua vida? Por quê? (h) Como sua família e amigos veem o fato 
de você não ser mãe até o momento? (i) Você já ouviu falar sobre maternidade tardia? (j) Com quais fatores você pode relacionar o fato de não ter sido mãe ainda? (k) Considerando a hipótese de ser mãe, como você se imaginaria quanto às atividades desempenhadas hoje, relacionadas com a maternagem?

\section{Procedimentos}

O projeto de pesquisa foi aprovado pelo Comitê de Ética em Pesquisa das Faculdades Integradas de Taquara (FACCAT/protocolo $\mathrm{n}^{\mathrm{0}}$ 708), conforme as normas e diretrizes da Resolução 196/96 do Conselho Nacional de Saúde - Ministério da Saúde. As mulheres foram convidadas a participar do estudo e agendou-se um encontro para a realização da coleta de dados. Assegurou-se às participantes o direito de participar ou não, bem como de desistir da pesquisa a qualquer momento. Todas as participantes assinaram o Termo de Consentimento Livre e Esclarecido (TCLE). As entrevistadas foram realizadas individualmente nas residências das participantes ou em seu local de trabalho, as quais foram gravadas em áudio para posteriormente serem transcritas. A ficha de dados sociodemográficos foi utilizada para a caracterização das participantes.

Utilizou-se o método qualitativo exploratório de pesquisa, o qual proporciona um vasto entendimento por meio da investigação experiencial sobre fenômenos múltiplos e suas representatividades (Denzin \& Lincoln, 2007). Para analisar os dados coletados na entrevista, foi utilizada análise de conteúdo (Laville \& Dionne, 1999). Após a leitura das entrevistas utilizou-se a sistemática proposta por Laville e Dionne para a preparação dos dados, a qual incluiu a descrição, a ordenação e a codificação dos dados a fim de gerar categorias de análise. Utilizou-se, para tanto, o modelo aberto de categorização, o qual permite a criação e a modificação das categorias ao longo do processo de exploração dos dados.

\section{Resultados e Discussão}

As quatro mulheres apresentaram escolaridade de nível superior e vida marital compartilhada entre dois e oito anos. A média de horas trabalhadas pelas mulheres durante a semana variou entre 44 e 80 horas, concomitantes a horas de estudos, que variaram de 12 a 56 horas. A renda salarial das participantes foi de três a quinze salários mínimos. Os resultados mostraram também que as participantes dedicam grande parte de seu tempo ao trabalho e ao estudo. Elas também contribuem, de forma significativa, para renda da família e, em alguns casos, são o principal provedor de seu núcleo familiar. Esses resultados corroboram dados da Pesquisa Nacional por Amostra de Domicílios de 2006 (PNAD), segundo a qual a mulher contemporânea é o símbolo de referência de seu núcleo familiar: $79 \%$ são referenciadas como chefe da família enquanto $25 \%$ dos homens são vistos como tal. Dados dessa mesma pesquisa (IBGE, 2006) mostraram que o número de tarefas laborais com vínculo empregatício da mulher cresceu aproximadamente $5 \%$ em relação à ocupação de trabalho do homem, a qual decaiu para $1 \%$ entre os anos de 1996 e 2006. O fato das participantes dedicarem tanto tempo ao estudo pode estar relacionado à necessidade de especialização e de qualificação constantes para que se mantenham no mercado de trabalho.

Após a análise de conteúdo das entrevistas, foram construídas três categorias: (a) multiplicidade de papéis da mulher contemporânea, a qual apresenta conteúdos relacionados ao trabalho, à formação profissional e ao impacto da multiplicidade de papéis na vida da mulher, (b) reflexões sobre maternidade, a qual narra conteúdos relacionados às justificativas sobre o fato de ainda não ser mãe, aos sentimentos acerca da maternidade tardia e aos aspectos positivos e negativos da maternidade tardia, e (c) maternidade tardia versus rotina atual, que descreve a relação entre a maternidade tardia e a rotina da mulher contemporânea. A seguir, apresentam-se os resultados referentes a cada uma destas categorias.

\section{Multiplicidade de Papéis da Mulher Contemporânea}

A primeira subcategoria desta categoria foi Trabalho, na qual se incluíram as seguintes temáticas: (a) inserção no mercado de trabalho, (b) alto número de horas trabalhadas e (c) tra- 
balho em primeiro lugar. As participantes mencionaram o trabalho como a principal atividade desempenhada, conforme relatou Diana: " $A$ atividade mais desempenhada?... O trabalho. Mais do que lazer, mais do que cuidar de mim, academia, médico, é o trabalho mesmo". Outro dado que chamou atenção para o fato de que a mulher dedica grande parte de seu tempo ao trabalho foi o alto número de horas dispensadas nesta atividade. Além disso, o trabalho é visto pelas participantes como sua principal fonte de satisfação, tanto do ponto vista profissional como do financeiro. Observou-se que o trabalho ocupa um lugar central na vida das participantes, conforme relataram Diana: "Hoje, se eu for fazer, inconscientemente, uma lista de prioridades, é o meu trabalho que vem em primeiro lugar" e Ana: "O meu trabalho pra mim é superimportante, eu gosto e quero me especializar mais nisso, é o que eu faço e quero continuar fazendo e me sentindo bem por isso". Elas se sentem recompensadas por realizarem atividades que ajudam outras pessoas, que lhes oportunizam aprender coisas novas e por sentirem que são capazes de tomar decisões por conta própria. No entanto, relatam uma preocupação com o mercado de trabalho, uma vez que o mesmo fornece poucas chances de crescimento e reconhecimento profissional (Possatti \& Dias, 2002).

Neste sentido, uma pesquisa realizada com mulheres trabalhadoras brasileiras destacou que as suas expectativas transcendem o "formar uma família", ou seja, a satisfação pessoal e financeira também é considerada como um anseio importante (Losada \& Rocha-Coutinho, 2007). Associados à autonomia feminina, existem alguns fatores que contribuem para a saída da mulher de casa, corroborando a diversidade de papéis, entre eles, as exigências impostas pela sociedade que valoriza e qualifica a atividade laboral fora do lar (Losada \& Rocha-Coutinho, 2007).

A segunda subcategoria foi Formação profissional, na qual se agruparam as percepções das participantes sobre a importância de realizarem especializações. Observou-se que, além de se dedicarem ao trabalho, as participantes também se dedicam aos estudos. $\mathrm{O}$ fato de continuarem estudando está relacionado à necessidade de permanecerem se especializando para se manterem atualizadas e garantirem sua posição no mercado de trabalho. Pode-se pensar, ainda, que a formação profissional - através de infinitas especializações - está relacionada à busca por um lugar no meio profissional e à conquista de um status social considerado adequado pelas participantes, conforme explicou Laura: "A mulher vem assumindo posições de destaques... e aí, cada vez mais, a mulher precisa buscar se especializar, pois as exigências são maiores e aí a gente vê essa mulher que exerce múltiplas funções".

Tais resultados indicam que a dedicação da mulher para garantir sua inserção no mercado de trabalho é bastante intensa, ou seja, parece que para conquistar um espaço laboral, a sua dedicação e investimento em trabalho e estudo deve ser o centro de sua rotina cotidiana. Ainda que, nos últimos anos, dados do Instituto Brasileiro de Geografia e Estatística (IBGE) destaquem maior distribuição de renda entre homens e mulheres, a desigualdade permanece, sendo as mulheres mais desfavorecidas (IBGE, 2010). Neste sentido, uma investigação realizada com 45 mulheres executivas brasileiras evidenciou que a busca pela realização profissional é um desejo vital e um meio para o alcance de relações mais igualitárias nas instâncias profissionais e pessoais (Maluf \& Kahhale, 2010).

A terceira subcategoria, Impacto da multiplicidade de papéis na vida da mulher, incluiu os seguintes aspectos: (a) falta de tempo para o lazer, (b) falta de tempo para a família, (c) falta de tempo para cuidar da saúde e (d) problemas emocionais e de saúde. Os resultados desta categoria indicaram que tanto empenho com o trabalho e com a formação profissional trazem alguns prejuízos à vida da mulher contemporânea. A falta de tempo para o lazer foi mencionada por todas as participantes como a principal consequência de sua rotina de trabalho e de estudo, conforme relatou Laura: "As minhas horas de lazer são reduzidas ao domingo, quando eu não venho pra empresa trabalhar, então a gente tem um lazer muito reduzido que causa um desgaste bastante grande". Como consequência da falta 
de tempo para o lazer, as participantes relataram que os momentos com a família também são reduzidos:

"Há um problema sério: meu marido eu encontro no domingo, por que ele também trabalha até umas 23h, no sábado até 21 horas, e eu não o encontro muito durante a semana. Eu trabalho à noite também, portanto quando ele chega do trabalho eu não estou, quando eu saio de manhã ele está dormindo" (Laura).

As participantes mencionaram, ainda, que têm muito pouco tempo para cuidar de sua própria saúde, o que, em muitas situações, gera problemas relacionados à sua saúde física e emocional, conforme relatou Diana:

"Prejuizo? Talvez na saúde né, me sinto mais ansiosa quando eu tenho muitas responsabilidades, realmente reduz minhas horas de lazer, distancia um pouco mais dos amigos, também dificulta a questão das atividades fisicas, então, ou eu acordo às $6 d a$ manhã pra caminhar, ou eu chego de noite muito cansada e vou dormir."

Além disso, os resultados mostraram que as participantes têm dificuldade de se distanciarem das questões do trabalho mesmo quando não estão trabalhando, conforme relatou Ana:

"É muito impactante... até em casa eu penso no trabalho, eu penso nas demandas que vão ocorrer, eu converso com o meu marido sobre trabalho, com meus amigos sobre trabalho... eu também penso que tenho que viver a minha vida."

Tais resultados demonstraram que o tempo da mulher contemporânea está muito mais voltado para atividades de trabalho e de estudo do que atividades de lazer e autocuidado. Isso pode ser observado na fala de Diana a qual manifestou "desejo de voltar no tempo", tempo no qual a mulher tinha menos obrigações de trabalho e no qual podia se dedicar mais ao lazer e ao convívio com a família. Diante deste relato, pode-se inferir que a mulher contemporânea está preocupada com as perdas e/ou prejuízos por ela sofridos em função do desempenho de tantos papéis. A sobrecarga dessas múltiplas tarefas foi observada por Souza et al. (2011), as quais, em um estudo sobre a interface família/trabalho para mães jovens e mães tardias, observaram que as atividades de cuidados pessoais e de lazer são relegadas com frequência a um segundo plano - mesmo quando a estabilidade financeira permite a contratação de profissionais para as auxiliarem.

Moreira e Nardi (2009) discutem os enunciados socialmente construídos sobre a maternidade, os quais passam a configurar as normas reguladoras das práticas maternas. $\mathrm{O}$ tempo de dedicação aos filhos é um dos importantes alicerces desses marcos regulatórios. Os autores refletem acerca dos limites individuais, dos desejos subjetivos de cada mãe, das necessidades e particularidades de cada filho, de cada família e de cada contexto, pois esses enunciados, por sua vez, produzem práticas restritas que causam sofrimento às mulheres. Os limites entre o socialmente esperado e o respeito às demandas de cada mulher/mãe parecem invisíveis em um momento social no qual a mulher coloca-se em plano de igualdade com o homem. Talvez por isso, aparece nas falas das participantes deste estudo o "desejo de voltar no tempo", evidenciando os impactos da multiplicidade de papéis na vida da mulher e a necessidade de reflexões acerca dessa temática.

\section{Reflexões sobre a Maternidade}

A primeira subcategoria desta categoria foi denominada Justificativas sobre o fato de ainda não ser mãe. Observou-se que as principais justificativas sobre o fato de ainda não serem mães estão relacionadas: (a) à busca de satisfação profissional como prioridade, (b) à busca pela independência financeira, (c) à busca pela constituição de uma relação estável, (d) ao fato de terem uma rotina exacerbada, e (e) à maternidade tardia como opção.

Quando questionadas sobre o fato de ainda não serem mães, as participantes têm muito claro quais as razões para isso, conforme explicou Paula: "Por que eu não tenho filhos hoje? Primeiro por causa do trabalho". A conquista da realização profissional aparece como a principal justificativa, a qual está intimamente ligada à busca pela independência financeira. Estes resultados ressaltam que a identidade da mulher con- 
temporânea está diretamente relacionada ao seu papel de trabalhadora e, consequentemente, à aquisição de sua independência financeira. Tais resultados corroboram os do estudo de Patias e Buaes (2012), o qual mostrou que mulheres que optam por não ter filhos valorizam a realização profissional e financeira e contestam representações sobre maternidade associadas a renúncias e sacrifícios em função de outra pessoa.

Após conquistarem um trabalho e seu sustento, as participantes revelaram que, para ser mãe, é preciso estabelecer uma relação estável, conforme relatou Paula: "tô há dois anos com meu companheiro, acho que preciso curtir mais algumas coisas, precisamos ter uma maior cumplicidade pra agregar, pra entrar um filho na nossa vida". Observou-se, ainda, que a construção de uma família com filhos está intensamente ligada às condições socioeconômicas da família, conforme mencionou Laura: "Atualmente é preciso ter para ser". Pode-se pensar que a vinda dos filhos é deixada para um futuro mais distante, onde seja possível mantê-los dentro das possibilidades socioeconômicas de cada participante.

Outra justificativa recorrente sobre o fato das participantes ainda não serem mães foi a rotina exacerbada de trabalho e de estudo, conforme relatou Diana: "Hoje, por exemplo, o objetivo era eu ser mãe com 35, mas isso se tornou inviável por que conciliou com as atividades do trabalho". Por fim, três participantes mencionaram que a maternidade tardia é uma opção consciente, ou seja, elas planejam ter filhos em um momento futuro, considerando que antes seria impossível em função de todas as suas atribuições, conforme mencionou Laura:

Acho até que pela evolução tecnológica, enfim, eu acho que a maternidade tardia é uma possibilidade que se tem, hoje é um recurso que se tem, até pra assumir com tudo isso que nós conversamos, com esse contexto da mulher na contemporaneidade, então eu acho que é uma possibilidade.

Esse resultado está em consonância com o estudo realizado por Gomes et al. (2008), o qual sugere que a gravidez tardia deveria ser considerada como um resultado tanto dos progressos da medicina como das mudanças sociais e não mais ser caracterizada como algo não natural.

Pode-se perceber que as mulheres têm se reconhecido de maneira distinta dos modelos antigos, a exemplo de suas mães em tempos passados. As mulheres das últimas décadas reivindicam direitos e desejos antes não concebidos às mesmas (Solomon, 2008). Ainda, pode-se inferir que a mulher que decide se dedicar à família após alcançar seu sucesso profissional, reconhece os benefícios de uma maternidade tardia. Esta ideia vai ao encontro do estudo de Zavaschi et al. (1999), segundo o qual a mulher que tem filhos com uma idade mais avançada pode recorrer a um ambiente familiar adequado e a melhores condições financeiras.

A segunda subcategoria, Sentimentos acerca da maternidade tardia, revelou que as participantes apresentam sentimentos diferentes e até divergentes sobre o fato de ainda não serem mães: (a) desejo de ser mãe e opção pela maternidade tardia, (b) desejo de não ser mãe, (c) medo de ser mãe, e (d) sentimentos relacionados à cobrança de familiares e de amigos.

Algumas participantes de fato optam pela maternidade tardia e têm um desejo claro de serem mães, conforme explicou Ana:

Eu penso em ser mãe. É assim, quando eu tinha 20 anos, eu pensava em ter com 28 anos, quando eu fiz 30 eu passei pros 32, agora que eu tenho 35 agora eu tenho até os 36 ou 37 anos. Então esse é meu prazo.

Por outro lado, outras participantes afirmam não desejarem ter filhos e justificaram essa escolha em função dos medos que sentem frente à maternidade, conforme mencionou Diana:

Uma criança, ela requer muitos, muitos anos, ela requer muito de ti, e como eu sou uma pessoa muito independente, tanto emocionalmente como financeiramente, sei lá eu tenho certo pânico de ter um ser vivo dependendo de mim o tempo inteiro, pra comer, ou seja, pra viver.

Os resultados de uma pesquisa com mulheres que optaram por não ter filhos mostraram que a decisão de não ser mãe parece indicar uma preferência por constituição de vínculos que 
não exijam tantos sacrifícios e que possibilitem maior liberdade (Patias \& Buaes, 2012).

Outro aspecto que merece destaque está relacionado ao que as participantes sentem com relação à cobrança de familiares e de amigos sobre o fato de não serem mães. Observou-se que, ora as famílias e os amigos demonstram ter um entendimento sobre a opção pela maternidade tardia, tratando-a com normalidade e sem cobrança, ora cobram à mulher que decide ter filhos mais tarde, questionando sua decisão. A fala de Diana ilustra a primeira situação: "Eles até admiram o fato do meu trabalho, das minhas urgências, então pra eles isso parece ser mais importante do que o fato de ser mãe". Já a cobrança aparece de forma explícita no relato de Ana: “. . . Todo mundo me cobra. Hoje menos, por que eu já tive muitas brigas com muitas pessoas, meus amigos sempre me cobram, as minhas irmãs sempre me cobraram e já brigamos várias vezes". Tais resultados indicam a preocupação das mulheres em serem discriminadas por suas famílias quando, em função de reconhecimento profissional, postergam a construção de suas famílias.

Percebe-se certa ambivalência na fala das participantes no que tange a percepção que elas têm sobre suas capacidades. Elas desempenham múltiplos papéis, uma diversidade grande de tarefas e, mesmo assim, sentem-se amedrontadas frente à demanda de ser mãe. Interessantemente, toda a segurança conquistada no universo profissional parece não ser suficiente para que se sintam seguras em relação à maternidade. A idade pode ser um fator que colabora para a noção da responsabilidade perante a maternidade, o que pode gerar maiores níveis de exigência e, consequentemente, de insegurança.

De fato, as mulheres de hoje vivem em um período histórico complexo, divididas entre o anseio de se afirmar como protagonistas no contexto profissional, econômico, político e social junto aos homens, e o desejo de se tornarem mães (Maluf \& Kahhale, 2010). Tal complexidade de demandas pode gerar essas ambivalências. Moreira e Nardi (2009) ressaltam que existe um contraste entre o tempo de conquista das condições que são compreendidas como necessárias para o nascimento de um filho (estabilidade profissional, financeira e conjugal) e tempo biológico (período de fertilidade e disposição atribuída à juventude), aspecto que pode propiciar certo descompasso na realização de ambos os projetos.

$\mathrm{Na}$ terceira subcategoria, Aspectos positivos e negativos da maternidade tardia, observaram-se os prós e contras da maternidade tardia. Entre os aspectos positivos, as participantes mencionaram a maturidade da mulher e suas melhores condições financeiras, conforme relatou Ana: "Já ouvi falar sobre maternidade tardia, nos beneficios da maturidade da mãe, do pai, da relação, de ter uma estrutura psicológica melhor, emocional e financeira também". Entre os aspectos negativos, foram mencionados os riscos para mãe e para o bebê devido à idade avançada da mãe e a perda da independência, tanto financeira como emocional, conforme disse Ana: "Também tem o outro lado, as complicações... após os 35 anos existem complicações para as mulheres e para as crianças... e esse foi um dos motivos que eu to me dando um limite de 38 anos pra engravidar".

A mulher se vê dividida dentre as diversas opções que lhe são impostas. Essas escolhas a levam por trajetórias nem sempre fáceis de serem trilhadas, algumas vezes, até, entrecruzadas. A sociedade, ao mesmo tempo em que a cobra para que seja uma profissional competente, parece exigir que a mulher somente se sinta completa ao ser mãe. Entretanto, com a diversidade de papéis exercidos por ela, há a dúvida da maternidade e a questão de ter uma idade ideal para tornar-se mãe, uma vez que, para a biomedicina, a maternidade tardia está associada a riscos (Zavaschi et al., 1999).

\section{Maternidade Tardia versus Rotina Atual}

Esta categoria abrange as percepções das participantes sobre como seria exercer a maternidade e dar conta da sua rotina atual ao mesmo tempo. As subcategorias elencadas foram: (a) necessidade de reorganização da rotina e (b) sentimento de preguiça frente à maternidade. Ao se imaginarem sendo mães, as participantes puderam pensar de forma prospectiva sobre como 
seria suas vidas caso tivessem um filho. Os resultados da primeira subcategoria mostraram que o principal aspecto mencionado pelas participantes foi a preocupação em readequar a rotina de trabalho e de estudo para a chegada de um filho. Para Laura, abrir espaço para um bebê foi visto como tão complicado, que ela mencionou a necessidade de "procurar ajuda de um psicólogo para lidar com a maternidade tardia".

Por sua vez, os resultados da segunda subcategoria referem-se especificamente ao sentimento de preguiça relatado pelas participantes frente à maternidade, conforme mencionou Diana: "Me dá preguiça em pensar em ser mãe". Considerando-se que já realiza uma série de tarefas cotidianamente, o sentimento de preguiça expresso por Diana parece estar mais associado à falta de ânimo para desempenhar mais um papel em sua vida - o qual certamente irá lhe exigir muito - do que a uma possível desvalorização da maternidade. Além disso, sabe-se que mulheres que se tornam mães após os 35 anos de idade podem não ter mais a disposição física e a energia necessárias para os cuidados com crianças na primeira infância (Cecatti et al., 2000; Moreira $\&$ Rasera, 2010).

O modo de ser mulher na atualidade parece marcado pela necessidade de independência, o qual, por sua vez, faz alusão ao discurso individualista. Quando extremado, esse discurso produz uma necessidade do sujeito provar sua independência, a qual só pode ser vislumbrada na lógica individual. Nessa lógica, só pode ter filhos quem tiver alcançado esse ideal (Moreira $\&$ Nardi, 2009). O perigo é quando esse ideal torna-se inatingível, pois vivemos em um mundo instável e imprevisível. Esse contexto ideológico pode ser o propulsor para tais inseguranças e receios perante a maternidade.

\section{Considerações Finais}

Neste estudo, buscou-se investigar a multiplicidade de papéis exercidos pela mulher contemporânea e sua relação com a maternidade tardia. Os resultados mostraram que há uma exigência - tanto interna quanto externa - de que a mulher estude, trabalhe, progrida profissional- mente e seja sua própria mantenedora. Essa sobrecarga de trabalho, não acontece sem que haja perdas. A falta de tempo e de cuidados em relação à saúde são alguns dos prejuízos que ocorrem em função da excessiva dedicação ao trabalho. Mesmo assim, as mulheres sentem-se felizes por poderem ocupar seu posto de trabalho, o que indica certa contradição. Pode-se observar ainda, que o trabalho está relacionado com a fonte de satisfação pessoal e financeira, diferentemente do que era esperado e/ou desejado pela mulher nos séculos XIX e XX, quando seu papel restringia-se ao de ser uma boa esposa e mãe.

A temática da multiplicidade de papéis e da maternidade tardia parece estar envolta em contradições: se, por um lado, a mulher se vê como uma profissional muito competente, por outro, ela teme em assumir a maternidade. Dentre as diversas causas explicativas, a idade mais avançada pode ser um fator propulsor dessa noção de responsabilidade da mulher perante a vinda de um filho e, ainda, como salientam Moreira e Nardi (2009), a ideologia vigente que preconiza o individualismo. Ter um filho em uma sociedade em que cada um é responsável por si próprio e na qual se almeja uma estabilidade inatingível é um contexto propício para a produção de inseguranças, medos e ambivalências.

Além disso, há o fator tempo. Para realizar todas essas tarefas quanto ao trabalho e ao estudo a mulher precisa de tempo. O mesmo tempo que ela precisaria para se dedicar à maternidade. Nesse contexto, pode-se dizer que: (a) o adiamento da maternidade é uma consequência de todas as demandas que a mulher do século XXI tem vivenciado e (b) a maternidade continua sendo um projeto de vida das mulheres, independentemente do momento histórico vivenciado. $\mathrm{O}$ que se observa, é que tanto o projeto profissional quanto o projeto de construção de uma família são importantes. Entretanto, o projeto relativo ao trabalho deve ser alcançado antes do projeto familiar. Por isso a maternidade se torna tardia. Assim, ao contrário de ser considerada como uma exceção à regra, a maternidade tardia é uma opção válida para as mulheres que desejam ter filhos e que já ultrapassaram os 35 anos. Os avanços da medicina e as mudanças sociais são 
indicativos de que cada vez mais a maternidade tardia deve ser vista como algo possível e natural e que pode trazer benefícios tanto para a mãe como para o bebê.

Nesta pesquisa, optou-se por entrevistar apenas mulheres do mesmo nível socioeconômico, o que consideramos uma limitação. Espera-se, no entanto, que os resultados deste estudo possam ajudar profissionais da área da saúde que trabalham com mulheres, casais e famílias que vivenciam questões relativas à maternidade tardia. Sugere-se que estudos futuros sejam realizados com participantes de diferentes níveis socioeconômicos. Além disso, sugere-se que outras pesquisas incluam não apenas mulheres, mas também homens e casais, a fim de investigar quais são suas impressões sobre a maternidade tardia. Por fim, recomenda-se, ainda, que estudos longitudinais sejam realizados para que o fenômeno da maternidade tardia possa ser investigado a partir de uma perspectiva de desenvolvimento humano.

\section{Referências}

Badalotti, M., \& Petracco, A. (1997). Idade e fertilidade. In M. Badalotti, C. Telöken, \& A. Petracco (Eds.), Fertilidade e infertilidade humana (pp. 101-113). Rio de Janeiro, RJ: Medsi.

Barbosa, P. Z., \& Rocha-Coutinho, M. L. (2007). Maternidade: Novas possibilidades, antigas visões. Psicologia Clínica, 19(1), 163-185. doi:10.1590/ S0103-56652007000100012. Recuperado em http://www.scielo.br/pdf/pc/v19n1/12.pdf

Bauer, M. W., \& Gaskell, G. (2002). Pesquisa qualitativa com texto, imagem e som: Um manual prático. Petrópolis, RJ: Vozes.

Carter, B., \& McGoldrick, M. (2008). As mudanças no ciclo de vida da família: Uma estrutura para a terapia familiar. Porto Alegre, RS: Artmed.

Cecatti, J. G., Aquino, M. M. A., \& Faúndes, A. (2000). Gravidez na idade materna avançada e na grande multípara. In B. Neme (Ed.), Obstetrícia básica (pp. 1202-1209). São Paulo, SP: Sarvier.

Denzin, N. K., \& Lincoln, Y. S. (2007). O planejamento da pesquisa qualitativa: Teorias e abordagens. Porto Alegre, RS: Artmed.
Grzybowski, L. S. (2002). Famílias monoparentais: Mulheres divorciadas chefes de família. In A. Wagner (Ed.), Família em cena: Tramas, dramas e transformações (pp. 39-53). Petrópolis, RJ: Vozes.

Fleck, A. C., Falcke, D., \& Hackner, I. T. (2005). Crescendo menino ou menina: A transmissão dos papéis de gênero na família. In A. Wagner, A transmissão dos modelos familiares (pp. 107121). Porto Alegre, RS: Editora da Pontifícia Universidade Católica do Rio Grande do Sul.

Fleck, A. C., \& Wagner, A. (2003). A mulher como a principal provedora do sustento econômico familiar. Psicologia em Estudo, 8, 31-38. Recuperado em http://www.scielo.br/pdf/pe/v8nspe/ v8nesa05.pdf

Gomes, A. G., Donelli, T. M. S., Piccinini, C. A., \& Lopes, R. C. S. (2008). Maternidade em idade avançada: Aspectos teóricos e empíricos. Interação em Psicologia, 12(1), 99-106. doi:10.5380/ psi.v12i1.5242. Recuperado em http://ojs. c3sl.ufpr.br/ojs/index.php/psicologia/article/ view/5242/9214

Hintz, H. C. (2001). Novos tempos, novas famílias? Da modernidade a pós-modernidade. Pensando Famílias, 3, 8-19.

Instituto Brasileiro de Geografia e Estatística. (2006). Pesquisa Nacional por Amostra de Domicílios - Síntese de indicadores. Rio de Janeiro, RJ: Autor. Recuperado em http://www.ibge.gov.br/ home/estatistica/populacao/trabalhoerendimento/pnad2006/sintesepnad2006.pdf

Instituto Brasileiro de Geografia e Estatística. (2010). Sintese dos indicadores sociais: Uma análise das condições de vida da população brasileira: Vol. 27. Estudos e Pesquisas: Informação demográfica e sócio econômica. Rio de Janeiro, RJ: Autor.

Laville, C., \& Dionne, J. (1999). A construção do saber: Manual de metodologia da pesquisa em Ciências Humanas. Porto Alegre, RS: Artmed.

Lima, L. C. (2010). Idade materna e mortalidade infantil: Efeitos nulos, biológicos ou socioeconômicos? Revista Brasileira Estado e População, 27(1), 211-226. doi:10.1590/S010230982010000100012. Recuperado em http:// www.scielo.br/pdf/rbepop/v27n1/12.pdf

Losada, B. L., \& Rocha-Coutinho, M. L. (2007). Redefinindo o significado da atividade profissional para as mulheres: $\mathrm{O}$ caso das pequenas 
empresárias. Psicologia em Estudo, 12(3), 493 502. doi:10.1590/S1413-73722007000300006 Recuperado em http://www.scielo.br/pdf/pe/ v12n3/v12n3a06.pdf

Maluf, V. H. D., \& Kahhale, E. M. S. P. (2010). Mulher, trabalho e maternidade: Uma visão contemporânea. Polêmica, 9(3), 143-160. Recuperado em http://www.polemica.uerj.br/ojs/index.php/ polemica/article/viewFile/54/100

Maux, A. A. B., \& Dutra, E. (2009). Do útero à adoção: A experiência de mulheres férteis que adotaram uma criança. Estudos de Psicologia (Natal), 14(2), 113-121. Recuperado em http:// www.scielo.br/pdf/epsic/v14n2/a04v14n2.pdf

Moreira, L. E., \& Nardi, H. (2009). Mãe é tudo igual? Enunciados produzindo maternidade(s) contemporânea(s). Estudos Feministas, 17(2), 569-594. doi:10.1590/S0104-026X2009000200015. Recuperado em https:// periodicos.ufsc.br/index.php/ref/article/view/ S0104-026X2009000200015/11354

Moreira, R. L. C. A., \& Rasera, E. F. (2010). Maternidades: Os repertórios interpretativos utilizados para descrevê-las. Psicologia \& Sociedade, 22(3), 529-537. Recuperado em http://www. scielo.br/pdf/psoc/v22n3/v22n3a13.pdf

Negreiros, T. C. G. M., \& Féres-Carneiro, T. (2004). Masculino e feminino na família contemporânea. Estudos e Pesquisas em Psicologia, 4(1), 34-47. Recuperado em http://www.revispsi.uerj. br/v4n1/artigos/Artigo\%203.pdf

Patias, N. D., \& Buaes, C. S. (2012). "Tem que ser uma escolha da mulher”! Representações de maternidade em mulheres não-mães por opção. Psicologia \& Sociedade, 24(2), 300-306. doi:10.1590/S0102-71822012000200007. Recuperado em http://www.scielo.br/pdf/psoc/ v24n2/06.pdf
Possatti, I. C., \& Dias, M. R. (2002). Multiplicidade de papéis da mulher e seus efeitos para o bem-estar psicológico. Psicologia: Reflexão $e$ Crítica, 15(2), 293-301. doi:10.1590/S010279722002000200007. Recuperado em http:// www.scielo.br/pdf/prc/v15n2/14353.pdf

Solomon, M. R. (2008). O comportamento do consumidor: Comprando possuindo e sendo. Porto Alegre, RS: Bookman.

Souza, I. F., Teixeira, K. M. D., Loreto, M. D. S., \& Bartolomeu, T. A. (2011). Não tem jeito de eu acordar e dizer: Hoje eu não vou ser mãe! Trabalho, maternidade e redes de apoio. Oikos: Revista Brasileira de Economia Doméstica, 22(1), 46-63. Recuperado em http://www.seer.ufv.br/ seer/oikos/index.php/httpwwwseerufvbrseeroikos/article/view/21/81

Schupp, T. R. (2006). Gravidez após os 40 anos de idade: Análise dos fatores prognósticos para resultados maternos e perinatais adversos (Tese de doutorado, Universidade de São Paulo, SP, Brasil).

Zavaschi, M. L., Costa, F., Brunstein, C., Kruter, B. C., \& Estrella, C. H. G. (1999). Idade materna avançada: Experiência de uma boa interação. Revista de Psiquiatria do Rio Grande do Sul, 21(1), 16-22.

Recebido: 12/03/2014

$1^{a}$ revisão: $30 / 04 / 2014$ Aceite final: 11/06/2014 